\title{
Present Status and
}

\section{Future Developments in the Electroplating of Gold}

\author{
Andreas R Zielonka \\ Forschungsinstitut fir Edelmetalle \\ und Metallchemie, Schwäbisch \\ Gmiind, Germany
}

The electrodeposition of gold has a long tradition. As far back as the first half of the 19th century, jewellery and 'objets d'art' were electroplated with gold, and the first patent covering electroplating of gold was filed in 1840 . Since that time, applications of electrodeposited gold coatings have extended far beyond the purely decorative fields and they are now widely used for their technical and functional properties. Gold coatings are currently in widespread use not only for jewellery, watches and spectacle frames but also in many branches of technology, e.g in electrical and electronic engineering. In a wide range of technical products, problem-free operation may be obtained only by utilising gold coatings.

\section{DECORATIVE APPLICATIONS}

If we first examine the field of decorative coatings, the enormous breadth of applications for gold is immediately apparent. In addition to the use of pure gold deposits, there is an increasing use of electrodeposited gold alloys as a final coating, in order to impart the desired surface properties and colour. By choice of the appropriate gold alloy as outer coating, the demands for the latest fashion trends can readily be met.

Another application of electrodeposition in the field of jewellery manufacture, is in the electroforming of hollow jewellery. The special merit of electroforming lies in the production of large decorative pieces which, were they not hollow, would be unacceptably heavy. Examples are large and voluminous earrings and other items where this technology is now essential. Initially, gold jewellery was electroformed in the 8 to 18 carat range. Today, however, electroforming processes are available to produce 24 carat jewellery. Moving away from its use in jewellery manufacture, the application of electroforming for the manufacture of gold jacket dental crowns should also be noted.

Another area of application for gold coatings which appears to have a promising future lies in the electrodeposition of composite gold layers. By suspending finely-divided inert particles in the gold plat- ing bath, a deposit is obtained in which these are incorporated. Such composite deposits often exhibit improved properties. Thus the inclusion of hard particles such as titanium nitride, silicon carbide or diamond results in a surface with greatly improved wearresistance. Composite coatings such as these are used in decorative as well as in technological applications. For improving wear-resistance in high carat gold deposits, the use of diamond particles as the inert phase produces the most satisfactory results.

Instead of the inclusion of hard particles to increase wear resistance, solid lubricant particles may be used to improve the sliding wear and reduce the frictional properties of gold coatings. Graphite or Teflon (polytetrafluoroethylene, PTFE) fall into this category. Yet another possible application might be the inclusion of coloured particles to modify the colour of the gold coating. Equally, selective electrodeposition of composites could be used to form a patterned surface.

\section{TECHNOLOGICAL USES}

Gold coatings are of major significance in electrical and electronic engineering. It is true that, in the past, efforts were made to reduce the amount of gold used for exam- 
ple in plug connectors in printed circuit board manufacture or in semiconductor manufacture. However, as components and assemblies become ever more complex, a correspondingly greater premium is placed on reliability and this has once more highlighted the unique nature of gold in such applications. Thus gold or its alloys may be used in order to meet the most specific demands in terms of hardness, wear-resistance, electrical contact resistance and corrosion resistance.

One of the outstanding merits of gold coatings is their resistance to corrosion, and this is important when safety is a vital factor, as in the aerospace or the automotive industries. In fact, gold has no rival in certain applications in these industries. For an example one might take the gold coating of air-bag sensors where correct functioning even after many years is critical. The value of gold used in this application is less than US $\$ 0.05$ per component.

When electroplating processes are considered, the corresponding environmental implications are often raised. It is difficult to completely avoid the use of hazardous materials in electrodeposition processes. In fact, there would seem to be no technical reasons why such problems should not be eliminated. On the other hand, there has never been a demand that use of electrical energy be avoided simply because in theory it can be hazardous. A hazard-free process operation, even one involving cyanides presents, at least in theory, no insuperable problem. If electroplating has a poor public image, then this is in large measure due to those plating plants where irresponsible or even criminal laxity in use of toxic species has occurred. Every effort should thus be made to ensure that proper procedures are observed in the conduct of electroplating processes in the industry. This apart, it should be noted that research and development continues apace, with the aim in view of minimising or even totally eliminating the use of hazardous materials in electroplating.

\section{NEW DEVELOPMENTS}

New or developing application areas for gold involve novel alloy systems, gold-matrix composite coatings and the use of gold in multilayer assemblies.

In the case of developments of new alloys, demands for decorative applications will emphasise the desired surface properties with respect to colour; hardness and corrosion and wear resistance. Composite coatings will find significantly increasing use in both decorative and technological applications. Thus, by the incorporation of inert species with a wide range of particle sizes and properties, deposit properties can be modified to meet the demands for numerous applications. A further possibility for creating new composite materials by electrodeposition lies in the deposition of multilayers. In these, thin layers of gold are deposited alternately with thin layers of a second metal to produce a coating with entirely new properties and functions. The scope for such multilayer structures extends way beyond that presently met by essentially homogeneous electrodeposited gold alloys even if these are multiphasic. The very special mechanical, electrical, magnetic and corrosion-protective properties of these multilayers are expected to give rise to a totally new range of applications.

From the wide range of uses already established for electrodeposited coatings, it is clear that electrodeposition is a key technology in the use of gold. Innovative processes will increase the importance of electrodeposition still further in the future.

\section{ABOUT THE AUTHOR}

Dr Andreas Zielonka is currently Deputy Director of the Forschungsinstitut für Edelmetalle und Metallchemie in Schwäbisch Gmünd, Germany, and has been involved in research and industrial development in the field of electrochemistry, electroplating and corrosion for 15 years. 